\title{
The Relationship of Trustworthiness and Ethical Value in the Healthcare System
}

\author{
Rajes Khana ${ }^{1}$, Manmeet Mahinderjit Singh ${ }^{2}$, Faten Damanhoori ${ }^{3}$, Norlia Mustaffa ${ }^{4}$ \\ School of Computer Science, Universiti Sains Malaysia, Penang-11800, Malaysia
}

\begin{abstract}
Females prefer discovering social media or healthcare systems to finding information and presenting their cases with any physician; however, the behavior of physicians tends to be uncontrollable on the healthcare system. Physicians have the capacity to share all of their patients' information with their colleagues without any permission or concern from the patients. For this reason, it is of utmost importance to design a breast self-examination system that can keep monthly track of self-exam data and communication between patient and physician. To develop such a system, identify the ethical values and trustworthiness as an indicator. Then, the survey will provide the details on ethical values and trustworthiness applicable in the system. Therefore, this research objective on the importance of ethical value and trustworthiness in the healthcare system. The survey on 772 respondents leading to the importance of the ethical value being used in the healthcare system is required. The ethical value of interaction, integrity, confidentiality, protection, caring, and fairness have a significant influence on the healthcare system. The path coefficients are answering Hypothesis $I$ in presenting the positive relationship and significant effect between ethical value and BSE system $(\mathrm{P}<.001)$. On the other side, trustworthiness has a significant influence on the healthcare system. The path coefficients are answering Hypothesis II in presenting the positive relationship and significant effect between trustworthiness and the BSE system $(P<.001)$. Finally, the relationship in healthcare between trustworthiness and ethical value is on integrity with honesty and belief.
\end{abstract}

Keywords-Ethics; ethical value; trustworthiness; breast selfexamination; healthcare system; social media

\section{INTRODUCTION}

Breast cancer mortality cases are growing every year, and it becomes the number one cancer cause for females [1]. In the country of the United States, India, Malaysia, and Indonesia, practicing breast self-examination in reducing breast cancer mortality [2]-[5].

The trend of using the internet and social media is growing every year. People are connected to over 3.5 billion using the internet and social media [6]. The demand for using social media brings healthcare to become the most important area to discuss [7], [8]. People are curious to get information on a particular disease on social media before meeting the physician. They prefer to looking for information from social media [7]. Many users in social media who were suffering from illnesses such as AIDS, breast cancer, or recovered from sexual abuse used social media as a convenient venue to discuss [9]-[11]. At the same time, physicians use social media for assisting, treating, and consulting with patients who are suffering from cancer [7], [12], [13]. Social media naturally creates an opportunity for the unethical person for accessing any person's private information and confidential information related to any disease while communicating with a physician [12]. However, the violation increasing on patient confidentiality in social media [14]-[18] and patients are lack trust in the physician's conduct [12], [19]-[21]. On the other hand, physicians $(65.8 \%, 187)$ are reluctant to use social media fully due to worries of protection on public access [13]. Therefore, the trust between patient and physician is needed [9] as well as ethical value should implement into the healthcare system [17].

The aims of this paper are the relationship between trustworthiness and ethical value on the interaction process between patient and physician in the use of the healthcare system. The objective is the importance of ethical value and trustworthiness in the healthcare system.

This study will describe the literature review, methodology, results, discussion, conclusion, and future challenges.

\section{LITERATURE REVIEW}

This section contains a brief discussion of the theory of ethics, the theory of trust, and the healthcare system.

\section{A. Principles of Ethics on Healthcare}

Belmont Report [22] introduces three principles of biomedical ethics; respect for persons, beneficence, and justice as mentioned in Table I. Follow by, Beauchamp \& Childress[23] bring four principles of biomedical ethics (Table I). There are:

1) Respect for autonomy, every person has their right to make their own life choices and free from any influences. Every individual should be able, to tell the truth, respected others' privacy, and the ability to protect confidential information.

2) Beneficence, every person should be able to respect their own decision and protecting themselves from harm. It involves secure patient welfare and promoting good.

3) Non-maleficence, as a person we are supposed not to hurt anybody, do not cause pain or suffer to others, and do not harm.

4) Justice, a person should be able to do services to other people fairly. They are serving two different persons in equal treatment. The justification of treatment should be equally the same among persons. 


\section{B. Theory of Ethics}

In the common term, ethics is part of accepting and analyzing moral life [23]. Philosophically, Ethics is "the branch of philosophy that explores the conduct of human character and human values rationally" [17]. The human character and human values were identified as what is good, bad, right, or wrong in a moral sense [25]. Every human conduct will generate an ethical value.

Ethical value is objects with value or as part of the human conduct being approval or disapproval [17], [26]. According to Khana et al. [17], ethical values consist of six values such as interaction, integrity, confidentiality, caring, and fairness. Those values carry 19 indicators such as communication, sharing information, clinician judgment, informed consent, patient interest as the priority, expert advice, honest information, respect, anonymity, responsibility, improving quality, clinical result, refrain harm, de-identification, safeguard, look up information, engagement, optimal care, and inequalities [12], [17], [27], [28]. In this study, ethical value identify as independent variable 1 (Table II).

\section{Analysis Relationship between Biomedical Ethics and Ethical Value}

The relationship between biomedical ethics and ethical value is presented in the Venn diagram in Fig. 1. The first principles of respect for autonomy carry, to tell the truth, respect privacy, and confidential information. Those indicators are related to the ethical value of integrity (respect), integrity (honest information), and confidentiality (clinical result). Tell the truth is the action of honesty which is related to honest information. Respect the privacy is related to respect in ethical value. Whereas confidential information is related to the confidentiality of clinical result information.

The second principle beneficence carries protect and defend the rights of others, prevent harm from occurring others, help persons with disabilities, and maximize possible benefits. Those indicators are related to the ethical value of protection and caring. Protect and defend the rights of others is related to protection (safeguard). Protection is the act of protecting somebody or something [29]. Prevent harm from occurring to others is related to protection (refrain harm). Refrain from harm is the abstain of doing harm to others. Especially physicians do not cause harm to the patients [17]. They help persons with disabilities related to caring (optimal care). The optimal care of any patient is essential for every physician [27]. Maximize possible benefits related to interaction (sharing information). A physician should share health-related information to the patient/public [12] to provide maximum benefits to them.

TABLE I. PRINCIPLES OF BIOMEDICAL ETHICS

\begin{tabular}{|c|c|c|}
\hline Belmont Report (1974) & Beauchamp \& Childress (1979) & Moral Rules \\
\hline \multirow{4}{*}{ Respect for Persons } & \multirow{4}{*}{ Respect for Autonomy } & a. Tell the truth $(B \& C)$ \\
\hline & & b. Respect the privacy of others (B\&C) \\
\hline & & c. Protect Confidential Information (B\&C) \\
\hline & & d. When asked, help others make important decisions (B\&C) \\
\hline \multirow{13}{*}{ Beneficence } & \multirow{7}{*}{ Beneficence } & a. Protect and defend the rights of others $(\mathrm{B} \& \mathrm{C})$ \\
\hline & & b. Prevent harm from occurring to others $(B \& C)$ \\
\hline & & c. Remove conditions that will cause harm to others (B\&C) \\
\hline & & d. Help persons with disabilities (B\&C) \\
\hline & & e. Rescue persons in danger $(\mathrm{B} \& \mathrm{C})$ \\
\hline & & f. Maximize possible benefits (BR) \\
\hline & & g. Minimize possible harms (BR) \\
\hline & \multirow{6}{*}{ Non-maleficence } & a. Do not kill (Gert) \\
\hline & & b. Do not cause pain or suffering (Gert) \\
\hline & & c. Do not incapacitate (Gert) \\
\hline & & d. Do not cause offense (Gert) \\
\hline & & e. Do not deprive others of the goods of life (Gert) \\
\hline & & f. Do not harm (BR) \\
\hline \multirow{6}{*}{ Justice } & \multirow{6}{*}{ Justice } & a. Everyone gets an equal share/Fair (BR) \\
\hline & & b. Distribution according to need (BR) \\
\hline & & c. According to individual effort (BR) \\
\hline & & d. According to societal contribution (BR) \\
\hline & & e. According to merit (BR) \\
\hline & & f. To each person according to free-market exchanges (B\&C) \\
\hline
\end{tabular}


TABLE II. ETHICAL VALUE VARIABLE ALONG WITH THE INDICATORS

\begin{tabular}{|c|c|c|c|}
\hline Variable & Sub-variables & Indicators & Definition \\
\hline \multirow{19}{*}{$\begin{array}{l}\text { Ethical Value } \\
\text { (EV) }\end{array}$} & \multirow{2}{*}{$\begin{array}{l}\text { Interaction } \\
(\text { INT) }\end{array}$} & Communication (INT1) & $\begin{array}{l}\text { Communication is the activity of expressing feelings and ideas or providing information to } \\
\text { another person [29]. In healthcare, communication is the way of conveying a self-condition to } \\
\text { the physician and vice versa[17]. }\end{array}$ \\
\hline & & $\begin{array}{l}\text { Sharing Information } \\
\text { (INT2) }\end{array}$ & $\begin{array}{l}\text { Sharing information is the process of the physician to deliver medical information to the } \\
\text { public[12] }\end{array}$ \\
\hline & \multirow{7}{*}{ Integrity (ITG) } & $\begin{array}{l}\text { Patient interest as the } \\
\text { priority (ITG1) }\end{array}$ & $\begin{array}{l}\text { The patient is critical in the healthcare world. They put patients as the highest priority to } \\
\text { compare with a physician [12]. Patient interest as the priority is the professional integrity of } \\
\text { physician that bring patient as the highest priority[23] }\end{array}$ \\
\hline & & Expert Advice (ITG2) & $\begin{array}{l}\text { Expert advice is a physician's capability to explain healthcare matters to society. It is part of } \\
\text { the trust given to the physician or any healthcare professional[12]. }\end{array}$ \\
\hline & & Honest Information (ITG3) & $\begin{array}{l}\text { A physician being honest to all his/her patient in relation to fees, promotion of any product, } \\
\text { and any conflict of interest[12]. }\end{array}$ \\
\hline & & Respect(ITG4) & Respect is part of respect for a person which is as a basis of the moral norm[23] \\
\hline & & Responsibility (ITG5) & Responsibility is part of the education given by the physician on a particular disease[12], [27] \\
\hline & & Improving Quality (ITG6) & To maintain the quality of clinical care and healthcare system[27] \\
\hline & & Clinician Judgment (ITG7) & Clinician judgment is the best of clinician outcome on patient health interest[27] \\
\hline & \multirow{5}{*}{$\begin{array}{l}\text { Confidentiality } \\
\text { (CFT) }\end{array}$} & Informed consent (CFT1) & $\begin{array}{l}\text { Informed consent is the consent of a person to undertake a medical procedure or any other } \\
\text { information[30]. }\end{array}$ \\
\hline & & Anonymity (CFT2) & Anonymity is an unknown person accessing a system without any identification[31], [32] \\
\hline & & Clinical Result (CFT3) & $\begin{array}{l}\text { The clinical result is the diagnosis data or historical data of the patient based on the } \\
\text { examination process[27] }\end{array}$ \\
\hline & & De-identification (CFT4) & $\begin{array}{l}\text { De-identification is a process of removing identifiers from health information and mitigating } \\
\text { privacy risks to individuals[33] }\end{array}$ \\
\hline & & $\begin{array}{l}\text { Look up information } \\
\text { (CFT5) }\end{array}$ & $\begin{array}{l}\text { To look up information is to find information on a particular patient's treatment on the internet. } \\
\text { It is part of the patient's privacy that is openly accessed in the public environment. It will } \\
\text { create a violation and a compromise of trust[12]. }\end{array}$ \\
\hline & \multirow{2}{*}{$\begin{array}{l}\text { Protection } \\
\text { (PRT) }\end{array}$} & Refrain harm (PRT1) & $\begin{array}{l}\text { Harmful is the condition of causing harm to other people, such as posting unprofessional } \\
\text { content[17]. }\end{array}$ \\
\hline & & Safeguard (PRT2) & Safeguard is the system that used a secure closed system with data encryption[12] \\
\hline & \multirow[b]{2}{*}{ Caring (CRG) } & Engagement (CRG1) & Engagement is the approach of the physician to convince the patient[12]. \\
\hline & & Optimal care (CRG2) & $\begin{array}{l}\text { Optimal care is the maximum effort of the physician to take care of the patient until the } \\
\text { clinical result/outcome appears[27]. }\end{array}$ \\
\hline & Fairness (FRS) & Inequalities (FRS) & $\begin{array}{l}\text { Inequalities are incomplete of medical evidence for physician decisions on patient } \\
\text { treatment[27]. }\end{array}$ \\
\hline
\end{tabular}

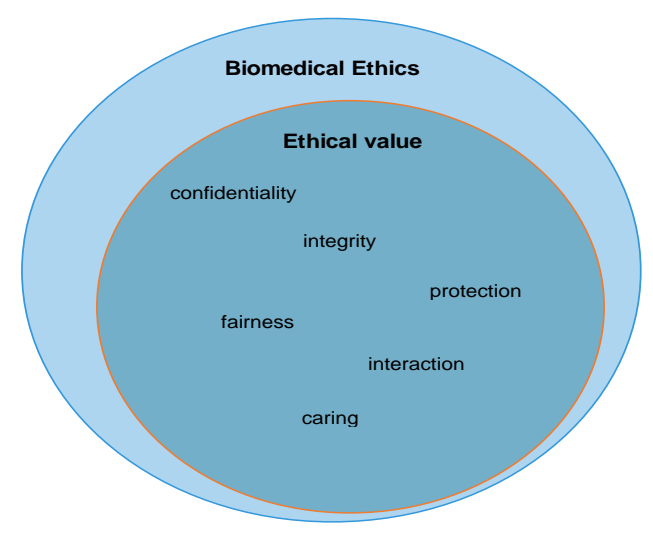

Fig. 1. Venn Diagram of The relationship between Biomedical Ethics with Ethical Value.

The third principle non-maleficence carries do not harm and do not cause pain. Those indicators are related to the ethical value of protection (refrain harm). Do not harm and do not cause pain is related to refrain harm of ethical value. Refrain harm is the action of abstaining from harm to others [17].
The fourth principle justice carries everyone gets an equal share/fair and distribution according to need. Those indicators are related to the ethical value of fairness. Every patient essentially must get equal treatment and avoid inequalities treatment [27].

\section{Theory of Trust}

Trust is "the willingness of a party to be vulnerable to the actions of another party based on the expectation that the other will perform a particular action important to the trustor, irrespective of the ability to monitor or control that other party" [34]. The trust definition applied to the relationship with another identifiable party that perceived to act and react based on willingness toward the trustor [34], [35]. Whereas, trustworthiness is the ability to be relied on as honest or truthful [29]. Trustworthiness also is considered as a virtual synonym for character or virtue on honesty and integrity in the context of health care [23], and it is context-dependent and personalized [36].

Mayer and Davis had introduced the trust principle. There are factors relating to the trustor and trustee that lead to trust. The trustor characteristic is based on the propensity to trust. The propensity to trust is the general willingness to trust 
others. At the same time, the trustee characteristic is based on trustworthiness. Trustworthiness is measured as the motivation to lie. For example, if a trustee will get something dishonest, he will be seen as less trustworthy [34].

Trust theory has moved to several areas of concern. This study brings trust concern on social media, especially to the healthcare area. Quinn et al. [37] introduce a personalized model of trustworthiness to cater to the internet environment and social media [36].

In this study, the enhancement of trustworthiness relationship in the healthcare system and its relationship with ethical value. The trustworthiness identifies as independent variable two which carries eight indicators such as honesty, reputation, competency, reliability, credibility, belief, confidence, and faith [36], [37], as mentioned in Table III.

\section{E. Healthcare System}

In this section, the healthcare system will define based on the breast self-examination system (BSE) due to the number of females who are suffering from breast cancer is growing. The estimated number on new cases 2,088,849 and mortality cases 626,679 [1], and around 87\% of posts on Facebook consist of cancer cases [8].
BSE is a method of doing breast examination on early detection from any abnormal fear of cancer [41]. BSE is an independent regular self-diagnostic technique done by a woman to observe any suspicious and changes on her breast through the use of a mirror [42].

Patients prefer to access social media with the facility that able to make appointments, receive reminders, diagnostic test results, provide information about their health, and as a forum for asking general questions [15]. There are some features requested by patients as a reference to develop the BSE system such as user account, calendar, self-exam wizard, history, chat room, location, knowledge, video tutorial, and forum.

In this study, the BSE system [43] identifies as a dependent variable that carries nine indicators, as mentioned in Table IV.

\section{F. Formulation of Research Hypothesis}

After reviewed ethical value, trustworthiness, and the BSE system, the researcher is formulating the research hypothesis, as mentioned below.

H1: Ethical value will positively affect the BSE system.

H2: Trustworthiness will positively affect the BSE system.

TABLE III. TRUSTWORTHINESS VARIABLE ALONG WITH THE INDICATORS

\begin{tabular}{|l|l|l|}
\hline Variable & Indicators & Definition \\
\hline \multirow{5}{*}{$\begin{array}{l}\text { Trustworthiness } \\
\text { (TW) }\end{array}$} & Honesty (TW1) & Honesty is one that makes good faith agreements, tells the truth, and fulfills any promises made[37]. \\
\cline { 2 - 3 } & Reputation (TW2) & $\begin{array}{l}\text { Reputation is part of the social notion of trust[38] or “an expectation about agent's behavior based on } \\
\text { information about the observation of its past behavior"[39]. }\end{array}$ \\
\cline { 2 - 3 } & Competency (TW3) & Competency is the ability of one person to fulfill another person's needs[37]. \\
\cline { 2 - 3 } & Reliability (TW4) & The quality of being trustworthy or of performing consistently well[29] \\
\cline { 2 - 3 } & Credibility (TW5) & The quality of being trusted and believed in[29] \\
\cline { 2 - 3 } & Belief (TW6) & Belief is justified and should be accepted(acceptable without argumentative support)[23] \\
\cline { 2 - 3 } & Confidence (TW7) & Confidence is "a feeling of certainty or easiness regarding a belief one holds"[40]. \\
\cline { 2 - 3 } & Faith(TW8) & Faith is the complete trust or confidence in someone or something[29]. \\
\hline
\end{tabular}

TABLE IV. BSE SYSTEM VARIABLE ALONG WITH THE INDICATOR

\begin{tabular}{|l|l|l|}
\hline Variable & Indicators & Definition \\
\hline BSE System (BSE) & User Account (BSE1) & A user account is privileged access by a user for keeping personal information safe. \\
\hline & Calendar (BSE2) & Calendar (Reminder system) for setting menstrual schedule as an alarm system. \\
\hline & Self-Exam Wizard (BSE3) & $\begin{array}{l}\text { Users are able to tap/sign/mark on the breast picture to plot the lesion area and share it with the } \\
\text { physician. And It has the capability to take a photo when the lump appears on the breast surface. }\end{array}$ \\
\hline & History (BSE4) & The function of this feature is to record all activity on breast self-examination. \\
\hline & Chat room (BSE5) & $\begin{array}{l}\text { The interaction or dialog privately between public/user and physician. User able to share her history } \\
\text { data on self-exam }\end{array}$ \\
\hline & Korum (BSE6) & The interaction or dialog publicly between public and physician \\
\hline & Location for Treatment(BSE8) & $\begin{array}{l}\text { The knowledge will provide information such as history, breast anatomy, breast cancer, diagnosis, } \\
\text { breast self-exam, and treatment }\end{array}$ \\
\hline & Physicians being informed by the patient for an appointment. \\
\hline
\end{tabular}




\section{METHODOLOGY}

The methods section will describe the research flow and research method and data collection.

\section{A. Research Flow}

The research flow in Fig. 2 describes the ethical phenomena in social media, supporting theory, identify the variable, the hypothesis of theoretical ethical framework, survey, validation proses, and finally ethical BSE system as the final outcome.

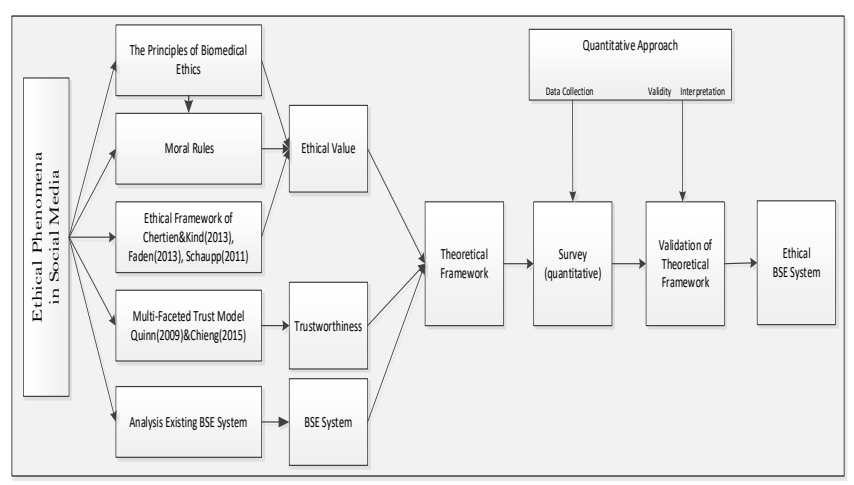

Fig. 2. Research Flow.

\section{B. Research Method}

The research method in this study is a quantitative approach. The quantitative design will do several steps on data gathering and analysis. There are identify participants, sampling size, reliability and validity, and the survey finding.

1) Participants: The questionnaire is distributed to potential participants such as doctors[44], and the public, which is taken to hospitals (doctors) and universities (students and lecturers). The study consent participants must be 18 years old and above, which is staying in the city of Jakarta, Indonesia[45]. The participants came from different backgrounds of study, and all were speaking and writing in the Indonesian language. The questioner has been designed into one form of instrument, whereas the instrument is designed into two languages, Indonesian and English (Appendices A.1).

2) Sampling size: The sampling size does base on target respondents. The target respondents are doctors and patients (outpatient females such as university students, housewives, or others). The sample size of doctors is based on the total population of doctors in Jakarta (the capital city of Indonesia). The total population of the doctor is 19536 [46], [47]. The sample size calculation for doctors based on the Slovin formula as mention below:

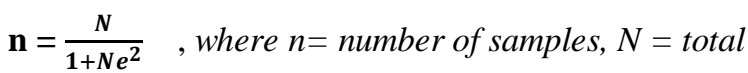

population and $e=$ error tolerance $(e=0.05)$ [48].

So, sample size for doctor is $\mathrm{n}=\frac{19536}{1+19536(0.05)^{2}}=392$ samples of the respondent.

Furthermore, the sample size for the patient (university student, housewife, or others) is an unknown population. So, the sample size is based on Partial Least Squares (PLS) guidance. PLS is important for structural equation modeling tools in developing theories for exploratory research, such as describing the independent variance variable on investigative the model. The sample size required by PLS is First, ten times the largest number of formative indicators used to measure a single construct (independent variable); Second, ten times the largest number of structural paths directed at a particular construct in the structural model[49]. The researcher has identified four variables, six sub-variables, and each subvariables includes 1-6 measuring indicators with a total of 38 indicators. The researcher chooses PLS as a suitable analytical tool to fit the small sample size requirement. In this case, the sample size was calculated based on a number of indicators, so ten times 38 equivalent to 380 . Therefore, the minimum sample size for patients is 380 .

3) Data analysis: A series of data analyses will be conducted on this study to test the research hypotheses. The data analysis through a quantitative approach is applied to structural equation modeling (SEM) in this study for identifying the relationship among observed variables. The correlation and multiple regression analyses will be executed from the collected quantitative[50], [51]. SEM consists of partial least squares SEM (PLS-SEM) and covariance-based SEM(CB-SEM). PLS-SEM is used to build theories by emphasizing on explaining the variance in the dependent variables while examining the model. Whereas, CB-SEM is used to accept or reject theories on a proposed theoretical model to estimate the covariance matrix as a sample data set[49]. This study prefers to used PLS-SEM due to less sample size required and simple on the multivariance normality[49]. Therefore, this method is appropriate for being used in the proposed model. PLS-SEM provides two main components: 1. Structural model, and 2. Measurement model. The structural model (represents the construct in circles) is the relationship between the variables(constructs). The measurement model is the relationships between the variables(constructs) and the indicator(represented in rectangles) [49].

4) Reliability and validity: The reliability is "a matter of whether a particular technique, applied repeatedly to the same object, yields the same result each time." Whereas validity is "the extent to which an empirical measure adequately reflects the real meaning of the concept under consideration" [52]. In other words, validity is "the extent to which differences found with a measuring instrument reflect true differences among those being tested" [53]. Reliability and validity will be addresses in quantitative.

In this study, the validity separated into internal validity and external validity [51], [54].

a) Internal validity is a causal claim by the researcher in a single experiment on the relationship between two variables. The result of correlation and multiple regression analysis will not guarantee the relationship of the variables between the independent variable and the dependent variable [55]. 
b) External validity is an inference validity on the effect of variables relationship results that being generalize to the population [55]. In phase 1: the significance value of the quantitative analysis indicates that the accessible population can be inferred from the sample in the study [51].

5) Survey findings: The instrument's strategies of printing and distribution were divided into several rounds until achieving the number of the valid questionnaire. In the first round, instruments were printed and distributed 1000 questionnaires. Those questionnaires were distributed to six hospitals and one university. Out of 1000 questionnaires, 772 valid questionnaires, 123 invalid questionnaires, and 105 questionnaires were not returned. The instrument has been designed for the ordinal scale data type, and the statistical analysis has been done through smartPLS 3.2.8.

\section{Results}

This section will describe demographics, descriptive statistics, analysis of the formative measurement model, analysis of the reflective measurement model, and the relationship analysis between trustworthiness and ethical value.

\section{A. Demographics}

This section is explaining the data related to the respondent's profile, such as profession, age, gender, education, and healthcare system user. Based on Table V has shown the total respondents are divided into two categories, doctors $51 \%$, and outpatient $41 \%$, whereas the outpatient dominated by female students. The target respondents of this study are females $75 \%$ and males $25 \%$ on using the BSE system. The respondents are dominated by experience users on using the healthcare system (72\%). In age, the respondents majority $18-29$ was $57 \%, 30-39(24 \%)$, and $40-49(12 \%)$. At the same time, education dominant by bachelor's degrees $51 \%$, followed by high school 24\%, master's degree 16\%, and Ph.D. $4 \%$. From the educational background, the researcher could categories most of the respondents are educated and aware of the healthcare system.

\section{B. Descriptive Statistic}

The descriptive statistic shows the indicators with mean, standard deviation, min, max, kurtosis, and skewness. The mean values are in the range of 3.968 to 4.367 for BSE1 (user account) and ITG7 (clinical judgment), which means the ITG7 (clinical judgment) as the highest implies by the users and BSE1 (user account) as the lowest implies by the users. The user accepts the integrity of physicians on their clinical judgment. In parallel, the mean values for interaction (INT1INT2), integrity (ITG1-ITG7), confidentiality (CFT1-CFT5), protection (PRT1-PRT2), caring (CRG1-CRG2), and fairness (FRS) is above 4.0, which means respondents agree that the use of BSE system must have ethical value on it. Moreover, the trustworthiness (TW1-TW8) shows a mean value above 4.0 with the lowest TW8 (faith) 4.100 and the highest TW6 (belief) 4.350, which means the respondents trust the BSE system. The indicator's value of kurtosis and skewness is less than the -1 and +1 range, meaning that the data is accepted as a normal distribution.
TABLE V. RESPONDENTS DEMOGRAPHIC

\begin{tabular}{|l|l|l|l|}
\hline Demographic & Category & $\begin{array}{l}\text { Count } \\
\text { (N=772) }\end{array}$ & Percentage \\
\hline \multirow{5}{*}{ Profession } & Doctor & 392 & $51 \%$ \\
& Outpatient: & 202 & $26 \%$ \\
& $\bullet \quad$ Student & 65 & $8 \%$ \\
& $\bullet \quad$ Housewife & 113 & $15 \%$ \\
\hline \multirow{3}{*}{ Gender } & $\bullet \quad$ Others & & \\
\hline \multirow{5}{*}{ Age } & Male & 195 & $25 \%$ \\
& Female & 577 & $75 \%$ \\
\hline \multirow{5}{*}{ Education } & $18-29$ & 189 & $57 \%$ \\
& $30-39$ & 94 & $24 \%$ \\
& $40-49$ & 41 & $5 \%$ \\
& $50-59$ & 6 & $1 \%$ \\
\hline Above 60 & High School & 183 & $24 \%$ \\
& Diploma & 40 & $5 \%$ \\
& Bachelor Degree & 393 & $51 \%$ \\
& Master Degree & 122 & $16 \%$ \\
& Ph.D. or equivalence & 34 & $4 \%$ \\
\hline system User's & Yes & 553 & $72 \%$ \\
& No & 219 & $28 \%$ \\
\hline
\end{tabular}

\section{Analysis of Formative Measurement Model}

The formative measurement model is the relationship between latent variables and the indicators. The development of the construct must consider the reflective and formative measurement model [49]. In this study, Ethical value has six sub-constructs, namely, interaction, integrity, confidentiality, protection, caring, and fairness are identified as formative measures. Those six sub-constructs are not correlated with each other. The valid measurements for ethical value are based on convergent validity, collinearity, and weight significance assessments [49]. Fig. 3 shows the ethical value measurement model based on smartPLS analysis, and each indicator carries a loading value.

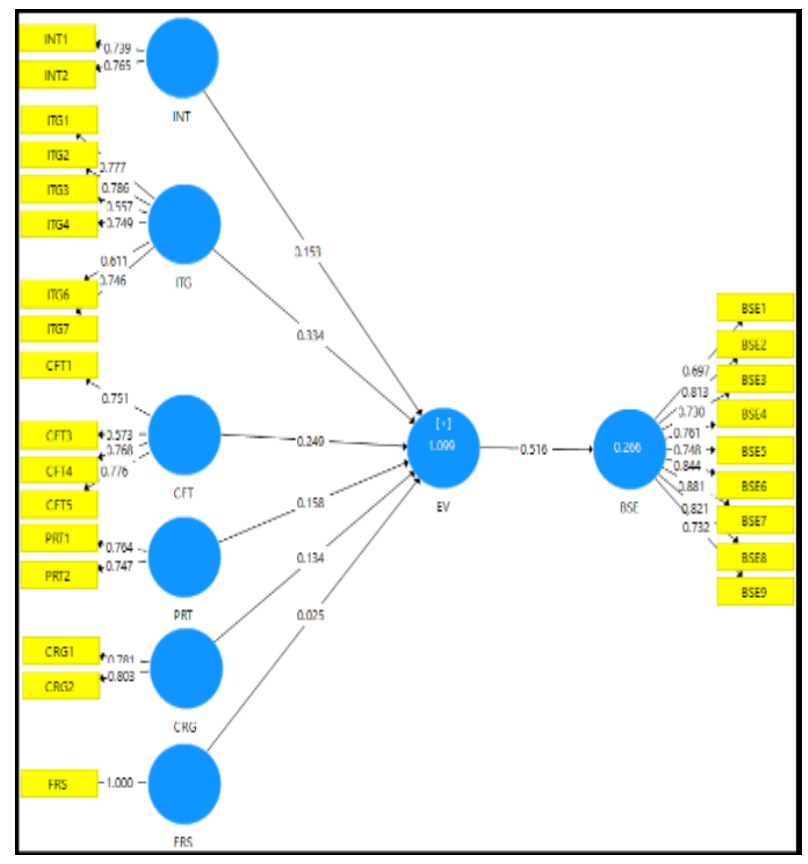

Fig. 3. The Formative Measurement Model of Ethical Value. 
Convergent validity is a positive measure that correlates with alternative measures of the same construct [49]. This validity will assess the degree construct indicators which are related to each other by getting their loadings, composite reliability (CR), and average variance extracted (AVE) in the outer model [56]. The observed of indicator loadings of interaction(INT), integrity (ITG), confidentiality (CFT), protection (PRT), caring (CRG), and fairness (FRS) are above 0.70 except for ITG3 (honest information), ITG5 (responsibility), ITG6 (improving quality), CFT2 (anonymity), and CFT3 (clinical result) indicators (Appendixes A). ITG5 (responsibility) and CFT2 (anonymity) indicators with a poor loading of 0.569 and 0.573 is then deleted to improve AVE scores of construct. The improvement of AVE score happened to confidentiality (CFT) from $\mathrm{AVE}=0.482$ to 0.521 , integrity (ITG) from AVE $=0.472$ to 0.504 after ITG5 and CFT2 deletion. Those improvements have been satisfying the requirement of CR and AVE scores above the thresholds [49]. Based on the results, convergent validity has shown the latent constructs measurements achieved their loading, CR, and AVE values have exceeded the criteria.

The collinearity assessment of ethical value makes sure the indicators represent the latent construct and not high level correlated between the indicator variables. At the same time, the measurement of collinearity is based on the variance inflation factor (VIF). The VIF values are five and higher that represents the collinearity problem. Therefore, the VIF value threshold should be below 5(Hair et al., 2017). The highest value of VIF, among other indicators, occurs to PRT1 $=4.205$, which means that not every ethical value indicator is part of the collinearity problem due to those indicators below the VIF threshold (Appendixes B).

To assess the formative measurement must look at each indicator weight of the t-value, and it significant to the indicator validity [57]. The significance level to measure the formative on ethical value is evaluated using a bootstrapping feature with 5000 subsamples [49]. The indicators of ethical value are significant at $\mathrm{p}<0.001$ for outer weights and outer loading. As a result, that component (interaction, integrity, confidentiality, protection, caring, and fairness) have causal relationships with the construct (ethical value).

\section{Analysis of Reflective Measurement Model}

The reflective measurement in the study is based on the construct (independent variables) of trustworthiness (IV2), BSE system (DV), and moderator of trust propensity. The analysis is similar to the formative measurement, which is evaluated based on convergent validity and discriminant validity. Fig. 4 represents the reflective measurement of trustworthiness (IV2), each indicator reflecting trustworthiness (IV2) based on an outer loading value above 0.5.

The convergent validity is on reflective measurement based on trustworthiness (IV2), BSE system (DV), and moderator of trust propensity. Similar to formative convergent validity, this validity will evaluate the construct outer loadings, composite reliability (CR), and average variance extracted (AVE). The convergent validity of reflective measures has shown the latent constructs measurements achieved their loading (>0.50), CR (0.60-0.95), and AVE (0.50) values have exceeded the criteria (Appendixes C).

The significance level to measure the reflective measures on trustworthiness and BSE system are evaluated using a bootstrapping feature with 5000 subsamples [49]. The indicators of trustworthiness and the BSE system are significant at $\mathrm{p}<0.001$ for outer weights and outer loading.

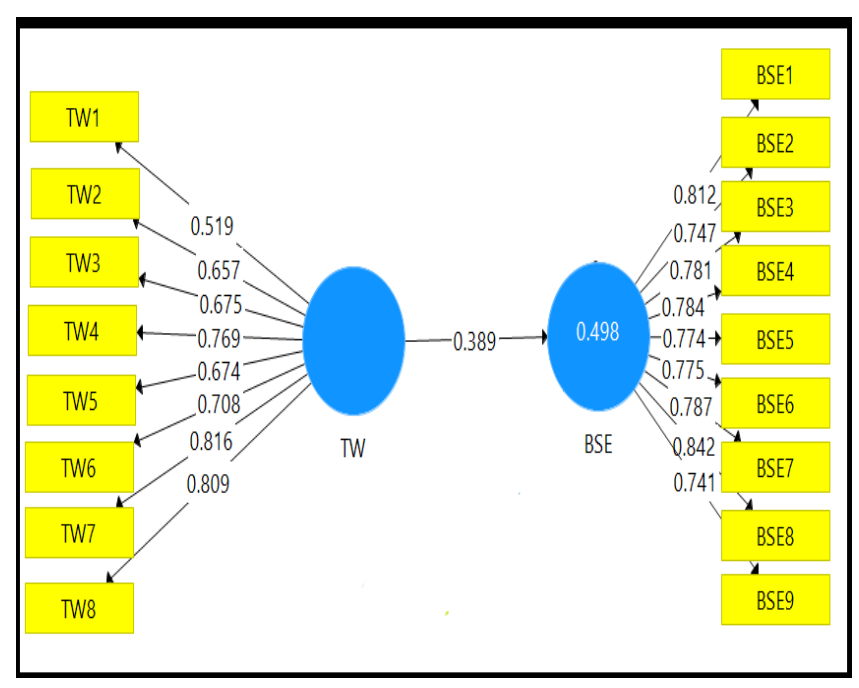

Fig. 4. Reflective Measurement of Trustworthiness (IV2).

\section{E. Analysis of Structural Model}

After the analysis of formative and reflective measurement is completed, the researcher proceeds with the structural model evaluation and hypothesis testing, whereas the evaluation is based on collinearity assessment, coefficient of determination and predictive accuracy, and path coefficients.

1) Collinearity assessment, the structural model evaluation should be first tested the collinearity assessment among the reflective measures. This evaluation to make sure during regression analysis not affected by collinearity problems [58]. The assessment for formative and reflective is based on inner VIF values. Table VI shows the inner VIF values for the independent variable (exogenous construct) in contradiction of the dependent variable (endogenous construct), which means that the model is far from collinearity problems (VIF value lower than five).

2) Coefficient of Determination $\left(R^{2}\right)$ is to evaluate the structural model by calculating the squared correlation between the actual dependent variable and predicted values. To evaluate the value of $R^{2}$ using smartPLS through consistent PLS algorithm and look at the quality criteria $\rightarrow R$ square as a result. The coefficient represents the combined effect of independent variables and dependent variables [49]. The value of $\mathrm{R}^{2}$ is 0.509 , meaning that $51 \%$ of the variance (BSE system) is explained by the independent variables (ethical value and trustworthiness). The $\mathrm{R}^{2}=0.509$ are identified as substantial since the basis of variance explanations above 50\% [59].

3) The path coefficients are the way to evaluate the significance and relevance of constructs path relationship. 
There are three criteria values accepted to conduct the twotailed test in PLS-SEM: 1.65 on significance level 10\%, 1.96 on significance level $5 \%$, and 2.57 on significance level $1 \%$ that depends on the study field [49]. The bootstrapping test with 5000 subsamples to execute path coefficients, standard errors, $\mathrm{t}$-Value, and confidence intervals. The significant results $1 \%$ level of $\mathrm{H} 1$ and $\mathrm{H} 2$, which is answering first and second research questions. Notably, the effect of trustworthiness on the BSE system with the highest path coefficient of 0.465 and significant $p<.001$.

The researcher provides the PLS path model illustrated in Fig. 5, all relationship and effects between the variables (constructs) are positive and significant ( $p$ values $=0.000$ )

Finally, the ethical framework on the BSE system has been valid on the bootstrapping test with 5000 subsamples shown in Fig. 5. The relationship between IV1-DV and IV2-DV.

\section{F. Analysis of the Relationship between Ethics and Trustworthiness in the Healthcare Field}

Based on the analysis of Venn diagram (Fig. 1), the ethical value indicators are part of the principles of biomedical ethics.

TABLE VI. COLLINEARITY STATISTICS FOR FORMATIVE AND REFLECTIVE MEASURES

\begin{tabular}{|l|l|}
\hline Construct & BSE System(DV) \\
\hline Ethical Value(IV1) & VIF: 2.257 \\
\hline Trustworthiness(IV2) & VIF: 3.287 \\
\hline Trust Propensity & VIF: 1.923 \\
\hline
\end{tabular}

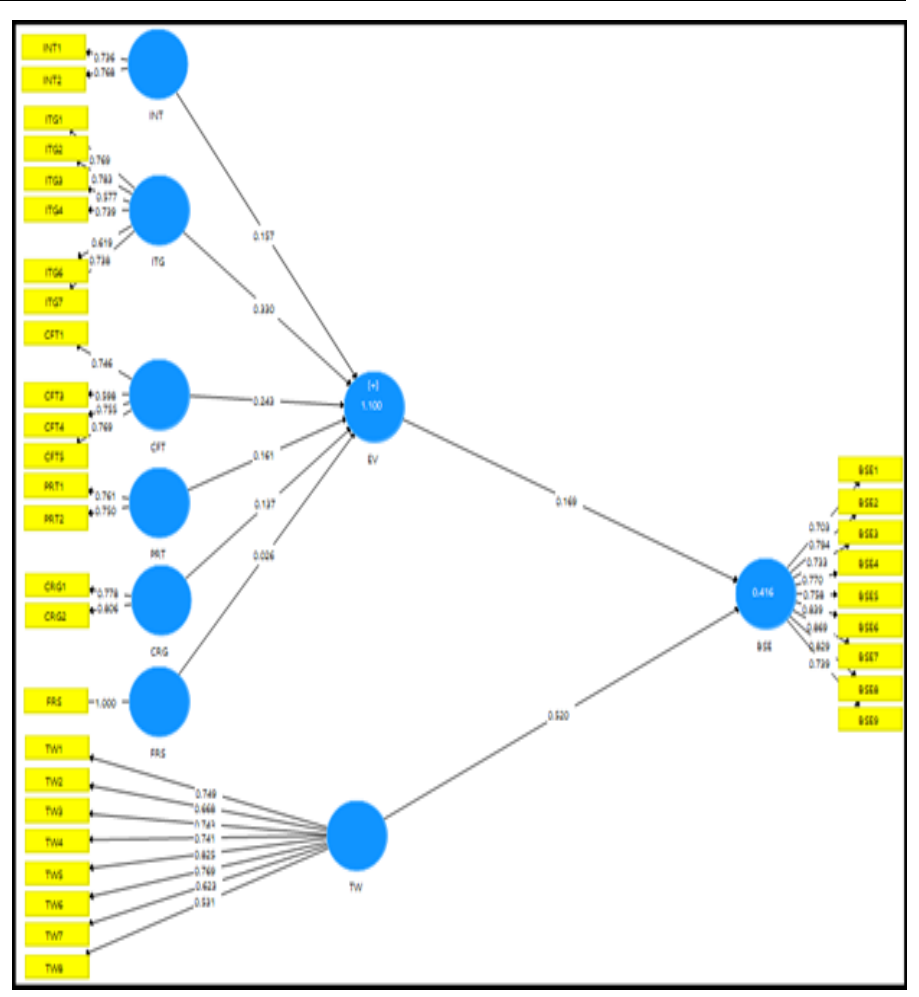

Fig. 5. Structural Model of Ethical Framework.
The relationship between ethics and trustworthiness in healthcare is presented in the Venn diagram in Fig. 6. Ethical value carries interaction, integrity, confidentiality, protection, caring, and fairness. Whereas trustworthiness carries honesty, reputation, competency, reliability, credibility, belief, confidence, and faith. Integrity brings several related indicators with trustworthiness. There is honest information (Table II) related to honesty (Table III). Honesty is telling the truth and fulfills any promises made [29], [37]. Respect is related to respect for autonomy (Table I). Whereas respect for autonomy is the right to hold views, to make choices, and take action based on personal values and beliefs [23]. The belief in ethics is related to the belief of trustworthiness. Therefore, respect is related to the belief of trustworthiness.

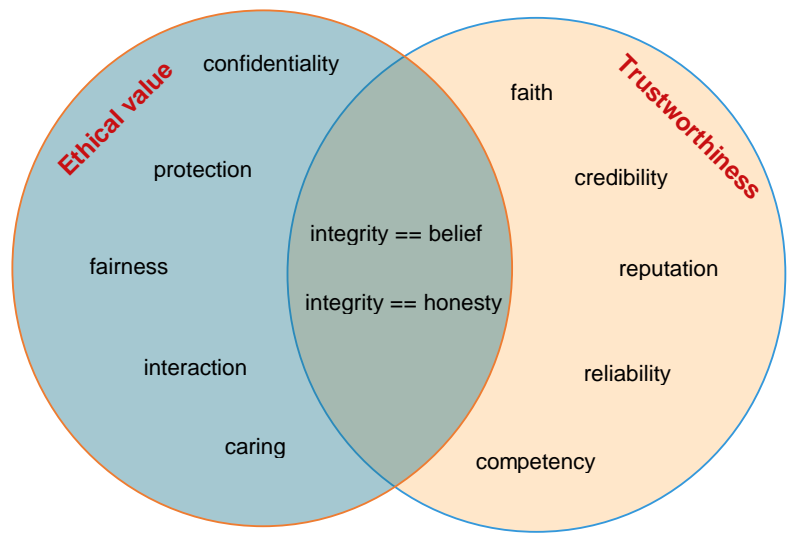

Fig. 6. Venn Diagram of the Relationship between Ethics and Trustworthiness.

\section{G. Relationship Analysis between Ethical Value and Trustworthiness on the Healthcare System}

1) The Relationship between Ethical value and trustworthiness:

- Based on the theory, ethics is an individual character of person and persons, which carries several aspects such as interaction, integrity (honest information), confidentiality, protection, caring, and fairness.

- Trust is the ability to be honest or truth to another person. The capability of being honest is part of human integrity. Once a person could tell the truth at any moment and situation, he/she will identify as a person with good integrity. Trust also carries several values such as honesty, reputation, competency, reliability, credibility, belief, confidence, and faith.

- Since honesty is one of the trust values, it will connect to the ethical value of integrity that carries "honest information" as the value. The relationship between ethics and trust is on the value of honesty. However, the honesty of ethical value emphasizes honest information, which identifies as an adjective. At the same time, honesty on trust emphasizes the action of the patient's statement saying the truth in the area of pain to the doctor. Doctors are telling the truth to the patient on the treatment given. 
2) The Differences between Ethical value and trustworthiness:

- Ethics emphasizes the overall individual character of a person or persons, whereas trust emphasizes on the capabilities of a person being honest or being truthful.

- The difference is in the scope of ethics and trust functions related to the healthcare system. The scope of ethics is to the physician, patient, and BSE system. At the same time, the scope of trust focuses on the trust of patients to the physician.

- Ethical value carries 19 indicators, whereas trustworthiness carries eight indicators. Moreover, the nineteen indicators of ethics and eight indicators of trust are not related to each other.

The 19 indicators of ethical value significantly influence the BSE system as well as trustworthiness, with eight indicators significantly influences the BSE system. The trustworthiness is emphasized in measuring physician direct performance, whereas ethical value carries 19 indicators to measure patient, physician, and healthcare systems.

\section{Discussion}

The main finding in this study is; first, the ethical value positively influences the BSE system. The correlation effect between the ethical value and the BSE system is significant $(\mathrm{P}<.001)$. Second, trustworthiness positively influences the BSE system. The correlation effect between trustworthiness and the BSE system is significant $(\mathrm{P}<.001)$.

There are 772 participants who are filled with a valid questionnaire consist of 51\% doctors and $49 \%$ outpatient female. The demographic of education background shown most of the respondents are educated and aware of the healthcare system.

Based on Fig. 3, the formative measurement model analysis has bring ethical value with a loading such as interaction (0.153), integrity (0.334), confidentiality (0.249), protection (0.158), caring (0.134), fairness $(0.025)$. Integrity becomes the most preferences of ethical value. Therefore, the physician should have good integrity when accessing the BSE system. The indicators of integrity with the loading are patient interest as the priority (ITG1) 0.777, expert advice (ITG2) 0.786 , honest information (ITG3) 0.557 , respect (ITG4) 0.749 , improving quality (ITG6) 0.611 , and clinician judgment (ITG7) 0.735 . Out of the seven indicators, the higher outer loading is ITG2 0.786 and ITG1 0.777 , which means that the "expert advice" and "patient as the priority" as the essential aspects of doctors and patients to be concerned. A doctor, as an expert able to provide a clear treatment solution on a particular disease [12]. In this case, the doctor as an expert to advise a patient based on their best treatment solution. Doctor integrity must put patients as their highest priority to compare with other things [12], [60]. Respect (ITG4) with loading 0.749 that concern between physician and patient must respect each other before interaction. A doctor must write a full respect narrative on social media [12] and respect the right of the patient [27]. Clinical judgment (ITG7) with loading 0.735, the capabilities of doctors to make a clinical judgment to a particular patient on her breast cancer disease. The clinical judgment must base on the scientific evidence and physician experience in treating the patient [27]. A patient expected an excellent clinical judgment from the doctor on their disease. Honest information (ITG3) with 0.557 that the honest information given by the patient will help a doctor to provide a solution, as well as the doctor, must be honest to inform to the patient related to the treatment and fees related [12].

The indicators of interaction are communication (INT1) and sharing information (INT2) with outer loading 0.882 and 0.887, which means that communication and sharing information as an essential aspect that influences the healthcare system. Physicians and patients must be able to identify communication in the healthcare system are credible [12]. The sharing of information within the community is essential to avoid strangers [28]. The indicators of confidentiality and the loading are informed consent (CFT1) 0.751 , the clinical result (CFT3) 0.573 , de-identification (CFT4) 0.768, and lookup information (CFT5) 0.776. The higher outer loading on lookup information 0.776 and informed consent 0.751 . The way a doctor to look up patient information as an essential part of the BSE system, and patient consent is necessary before accessing the data. In the open internet space, to look up patient information is not wrong [12] as patient consent exists. De-identification (CFT4) with loading 0.768 will help the patient to de-identify their self before meeting with the doctor. The capabilities of the system to be able to de-identify patient identity [12]. The feel of shameful while consultation with male doctors was solved. Clinical result (CFT3) with loading 0.573, the medical history of self-exam recorded along with the communication history with the doctor [27]. The indicators of protection are refrain harm (PRT1) and safeguard (PRT2) with the higher outer loading on refrain harm 0.764 and safeguard 0.747. A patient's medical history posted by a doctor with patient consent will refrain harm to the patient [12]. The healthcare system protection must base on the encryption mode [12]. With the encryption on the user account that the BSE system will secure the interaction between patient and physician. The indicators of caring are engagement (CRG1) and optimal care (CRG2) with the higher outer loading on engagement 0.803 and follow by optimal care 0.781 . The healthcare system is able to engage the patient's own care and perform quality assessment [12]. The capabilities of a system to make comfort to the patient and physician on accessing the system. Optimal care also helps the attention of a physician to provide the best treatment as the final outcome [27]. The indicator of fairness is inequality with loading 1 . Inequalities of scientific health evidence will create wrong clinical decisions [27]. The equalities of the clinical result will bring better treatment evidence on clinical decisions.

Fig. 4 shown reflective measurement model analysis on trustworthiness. The trustworthiness with eight indicators, such as honesty, reputation, competency, reliability, credibility, belief, confidence, and faith, carries a variety of loading values. The highest loading of the trustworthiness indicator is confidence (TW7) 0.816 , followed by faith (TW8) 0.809 , reliability (TW4) 0.769 , belief (TW6) 0.708 . Others are competency (TW3) 0.675 , credibility (TW5) 0.674 , reputation 
(TW2) 0.657 , and the lowest loading is honesty (TW1) 0.519 . When looking at the path relationship, trustworthiness has the strongest path coefficient relationship with the BSE system. The path coefficient 0.465 , t-value 11.667 and p-value 0.000 .

Confidence with loading 0.816 has a feeling of easiness related to the belief hold [40], which means a doctor and patient have good confidence while accessing the BSE system. Faith with loading 0.809 has the capability to fully trust something [61], which means the full trust of patients and physicians on the interaction process in the healthcare system. Reliability with loading 0.769 has the quality of being trustworthy based on the system [62], which means a doctor and patient expected a reliable medical history. Belief with loading 0.708 , belief is accepted without any doubt [23], which means the patient and physician accepted using the healthcare system without any doubt. Competency with loading 0.675 has the capability to fulfilled other person needs [37], which means the capabilities of a doctor to do treatment to every patient through the system. Credibility with loading 0.674 has the quality of belief in particular things [62], which means the capabilities of the healthcare system to support the need of patients and doctors. Reputation with loading 0.657, the expectation of an agent behavior from the information [39], which means doctors' reputation depends on the trust value given by the patients. Honesty with loading 0.519 , the promises made by a particular person as a good faith [37], which means doctors must keep their statement on explaining the case to a particular patient. As well as patients must saying the truth of their sickness to the doctor for correct treatment.

In the general healthcare field, the relationship between ethics and trustworthiness are related to each other (Fig. 5). Two indicators are related to each other (Fig. 6). The integrity of ethics and honesty of trustworthiness are related. As well as the integrity of ethics and honesty of trustworthiness are related.

The relationship between ethical value and trustworthiness in the healthcare system has been identified on the honesty indicator. However, Honesty is the indicator of trustworthiness as a noun, whereas honest information exists on an ethical value indicator as an adjective. Honesty emphasizes the action of the patient's statement to the physician in the area of sickness. Doctors are telling the truth to the patient on medical results. Therefore, there is no relationship between trustworthiness and ethical value in the healthcare system.

\section{CONCLUSION}

The study has confirmed an ethical value formative measurement model to predict the relationship with the BSE system. The relationship between ethical value and the BSE system has proved significant findings. On the other hand, the trustworthiness reflective measurement model to predict the relationship with the BSE system has proved significant findings. The relationship between ethical value and trustworthiness happens in honesty and belief indicators.

The implementation of ethical value and trustworthiness enables patients to be confident in using the BSE system.
Patients and physicians will be secure in using the healthcare system, which is protected by the ethical value.

\section{FutURE CHALLENGES}

The challenge of target participants happening due to a specialist of an oncologist is limited time for the survey. The survey is not specific to any particular race, culture, or religion and the study also focuses on the use of the BSE system.

\section{ACKNOWLEDGMENT}

The ethical code of this study was approved by the research ethics board of Esa Unggul University committee (No. 0155-20.133/DPKE-KEP/FINAL-EA/UEU/V/2020).

\section{REFERENCES}

[1] F. Bray, J. Ferlay, I. Soerjomataram, R. L. Siegel, L. A. Torre, and A. Jemal, "Global cancer statistics 2018: GLOBOCAN estimates of incidence and mortality worldwide for 36 cancers in 185 countries," CA. Cancer J. Clin., vol. 68, no. 6, pp. 394-424, 2018.

[2] L. M. Hassan et al., "Evaluation of effect of self-examination and physical examination on breast cancer," The Breast, vol. 24, no. 4, pp. 487-490, 2015.

[3] M. Y. Roth, J. G. Elmore, J. P. Yi-Frazier, L. M. Reisch, N. V. Oster, and D. L. Miglioretti, "Self-Detection Remains a Key Method of Breast Cancer Detection for U.S. Women," J. Women's Heal., vol. 20, no. 8, pp. 1135-1139, 2011.

[4] S. Solikhah, S. Promthet, N. Rakkapao, and C. P. Hurst, "Validation of an Indonesian Version of the Breast Cancer Awareness Scale (BCASI)," Asian Pac. J. Cancer Prev., vol. 18, no. 2, pp. 515-522, 2017.

[5] E. Sujindra and T. Elamurugan, "Knowledge, attitude, and practice of breast self-examination in female nursing students," Int. J. Educ. Psychol. Res., vol. 1, no. 2, p. 71, 2015.

[6] S. Kemp, "Digital in 2020," We Are Social Inc., 2020. [Online]. Available: https://wearesocial.com/blog/2020/07/digital-use-around-theworld-in-july-2020. [Accessed: 10-Aug-2020].

[7] M. Modahl, L. Tompsett, and T. Moorhead, "Doctors, Patients \& Social Media," QuantiaMD, 2011. [Online]. Available: whttp://www.quant iamd.com/q-qcp/social_media.pdf. [Accessed: 10-Aug-2020].

[8] T. Hale, A. Pathipati, S. Zan, and K. Jethwani, "Representation of health conditions on Facebook: content analysis and evaluation of user engagement," J Med Internet Res, 2014.

[9] K. Denecke et al., "Ethical Issues of Social Media Usage in Healthcare," IMIA Yearb. Med. Informatics, pp. 137-147, 2015.

[10] S. Fox, "Peer-to-peer Health Care," PewReseachCenter, 2011. [Online]. Available: www.pewinternet.org. [Accessed: 12-Dec-2016].

[11] M. White and S. M. Dorman, "Receiving social support online: Implications for health education," Health Educ. Res., vol. 16, no. 6, pp. 693-707, 2001.

[12] K. C. Chretien and T. Kind, "Social media and clinical care: Ethical, professional, and social implications," Circulation, vol. 127, no. 13, pp. 1413-1421, 2013.

[13] J. Brown, "How Doctors View and Use Social Media: A National Survey," JMIR mHealth uHealth, vol. 16, 2014.

[14] K. C. Chretien, S. R. Greysen, J.-P. Chretien, and T. Kind, "Online Posting of Unprofessional Conduct by Medical Students," Jama, vol. 301, no. 12, pp. 1309-1315, 2009.

[15] J. Fisher and M. Clayton, "Who Gives a Tweet: Assession Patients' Interest in the Use of Social Media for HealthCare," Worldviews Evidence-Based Nurs., vol. 9, 2012.

[16] S. R. Greysen, D. Johnson, K. C. Chretien, C. Gross, A. Young, and H. J. Chaudhry, "online professionalism investigations by State Medical Boards-First, DO NOT HARM,” Ann. Intern. Med., 2013.

[17] R. Khana, M. Mahinderjit Singh, F. Damanhoori, and N. Mustaffa, "Investigating the Importance of Implementing Ethical Value on a Healthcare System within a Social Media context," Int. J. Innov. Creat. Chang., vol. 12, no. 5, pp. 352-369, 2020. 
[18] C. L. Ventola, "Social Media and Health Care Professionals: Benefits Risks, and Best Practices," P\&T, vol. 39, no. 7, pp. 491-500, 2014.

[19] T. Kind, S. R. Greysen, and K. C. Chretien, "Pediatric clerkship directors' social networking use and perceptions of online professionalism," Acad. Pediatr., vol. 12, no. 2, pp. 142-148, 2012.

[20] S. R. Greysen, T. Kind, and K. C. Chretien, "Online professionalism and the mirror of social media," J. Gen. Intern. Med., vol. 25, no. 11, pp. 1227-1229, 2010.

[21] K. Krot and I. Rudawska, "The Role of Trust in Doctor- Patient Relationship : Qualitative Evaluation of Online Feedback," vol. 9, no. 3, pp. 76-88, 2016.

[22] Belmont Report, "Ethical Principles and Guidelines for the Protection of Human Subjects of Research," Washington D.C., 1974.

[23] T. L. Beauchamp and J. F. Childress, Principles of Biomedical Ethics, 6th ed. Oxford University Press, 2009.

[24] B. Gert, Its Nature Justification of Morality, Revised. Oxford University Press, 2005.

[25] J. P. Thiroux and K. W. Krasemann, Ethical Theory And Practice, 11th ed. Pearson, 2012.

[26] J. H. Tufts, “Ethical Value,” J. Philos. Inc., vol. 75, no. 11, pp. 664-677, 1908.

[27] R. R. Faden, N. E. Kass, S. N. Goodman, P. Pronovost, S. Tunis, and T L. Beauchamp, "An Ethics Framework for a Learning Health Care System: A Departure from Traditional Research Ethics and Clinical Ethics," Hastings Cent. Rep., vol. 43, no. SUPPL. 1, 2013.

[28] L. C. Schaupp, L. D. Carter, D. L. Schaupp, and N. C. a, "Ethics in Social Networking: A Framework for Evaluating Online Information Disclosure," Proc. 44th Hawaii Int. Conf. Syst. Sci. HICSS, pp. 1-7, 2011.

[29] A. Hornby, Oxford Advanced Learner's Dictionary of Current English. Oxford University Press, 2005.

[30] "Medical Dictionary," Farlex, Inc, 2003. [Online]. Available: https://medical-dictionary.thefreedictionary.com. [Accessed: 09-Aug2019].

[31] C. Rizza, P. Curvelo, I. Crespo, M. Chiaramello, A. Ghezzi, and Â. G. Pereira, "Interrogating Privacy in the digital society: media narratives after 2 cases 6 Interrogating Privacy in the digital society: media narratives after 2 cases," IRIE Int. Rev. Inf. Ethics, vol. 16, no. 12, pp. 6-17, 2011.

[32] M. Mahinderjit Singh, P. J. Ng, K. M. Yap, M. H. Husin, and N. H. A H. Malim, "Cyberbullying and a mobile game app? An initial perspective on an alternative solution," J. Inf. Process. Syst., vol. 13, no. 3, pp. 559-572, 2017.

[33] US-HHS, "Guidance Regarding Methods for De-identification of Protected Health Information in Accordance with the Health Insurance Portability and Accountability Act (HIPAA) Privacy Rule," Health and Human Services(HHS.gov), 2015. [Online]. Available: https://www.hhs.gov/hipaa/for-professionals/privacy/special-topics/deidentification/index.html\#rationale. [Accessed: 22-Oct-2019].

[34] R. C. Mayer and J. H. Davis, "An Integrative Model of Organizational Trust," Acad. Manag., vol. 20, no. 3, pp. 709-734, 1995.

[35] J. B. Rotter, "A new scale for measurement of interpersonal Trust," J. Pers., vol. 35, no. 4, 1967.

[36] L. B. Chieng, M. Manhinderjit Singh, Z. F. Zaaba, and R. Hassan, "Multi-Facet Trust Model for Online Social Network Environment," Int. J. Netw. Secur. Its Appl., vol. 7, no. January 2015, 2015.

[37] K. Quinn, D. Lewis, D. O. Sullivan, and V. P. Wade, "An Analysis of Accuracy Experiments Carried out over of a Multi-Faceted Model of Trust,” Int. J. Inf. Secur., vol. 8, no. 2, pp. 103-119, 2009.

[38] J. Golbeck and J. Hendler, "Accuracy of Metrics for Inferring Trust and Reputation in Semantic Web- Based Social Networks," no. April 2004, 2004.
[39] J. A. N. M. Leimeister and W. Ebner, "Design , Implementation, and Evaluation of Trust-Supporting Components in Virtual Communities for Patients,” J. Manag. Inf. Syst., vol. 21, pp. 101-135, 2005.

[40] D. H. McKnight and N. L. Chervany, "The Meanings of Trust," no. May, 1996.

[41] H. Thornton and R. R. Pillarisetti, “'Breast awareness' and 'breast selfexamination' are not the same. What do these terms mean? Why are they confused? What can we do?," Eur. J. Cancer, vol. 44, no. 15, pp. 2118-2121, 2008.

[42] J. L. Longe, The Gale Encyclopedia of Cancer "A guide to Cancer and its treatments," 2nd ed. ThomasGale, 2005.

[43] R. Khana, M. Mahinderjit Singh, F. Damanhoori, and N. Mustaffa, "Breast Self-Examination System Using Multi-Faceted Trustworthiness: Observational Study," JMIR Med. Informatics, 2020.

[44] P. White, "Getting health professionals to work together," BMJ, vol. 320, pp. 1021-1022, 2000.

[45] S. Kemp, "Digital in 2018: World's internet users pass the 4 billion mark," wearesocial.com, 2018. [Online]. Available: https://wearesocial.com/blog/2018/01/global-digital-report-2018. [Accessed: 13-Feb-2018].

[46] D. Budijanto, F. Sibuea, W. Widiantini, and Y. Aryantin, "Data dan Informasi Profil Kesehatan Indonesia 2018," Jakarta, 2019.

[47] IDI, Profil Dan Direktori Ikatan Dokter Indonesia. Jakarta: Ikatan Dokter Indonesia(IDI), 2018.

[48] T. P. Ryan, Sample Size Determination and Power. Canada: John Wiley \& Sons,Inc, 2013.

[49] J. F. Hair, G. T. M. Hult, C. M. Ringle, and M. Sarstedt, A Prime on Partial Lease Squares Sructural Equation Modelling (PLS-SEM). Sage Publications Asia-Pacific Pte. Ltd, 2017.

[50] J. W. Creswell, Research design, 4th ed. Sage Publications, 2014.

[51] S. Wong and P. Cooper, "Reliability and validity of the explanatory sequential design of mixed methods adopted to explore the influences on online learning in Hong Kong bilingual cyber higher education,” Int. J. Cyber Soc. Educ. Pages, vol. 9, no. 2, pp. 45-64, 2016.

[52] E. Babbie, The Basics of Social Research, Fifth Edit. United States of America, 2011.

[53] C. Kothari, Research Methodology "Methods and Technique," 2nd ed. New Age Int Publishers, 2004.

[54] M. Zohrabi, "Mixed Method Research: Instruments , Validity , Reliability and Reporting Findings," Theory Pract. Lang. Stud., vol. 3, no. 2, pp. 254-262, 2013.

[55] W. R. Shadish, T. D. Cook, and D. T. Campbell, Experimental and Quasi-Experimental Designs For Gneralized Causal Inference. Boston, New York: Houghton Mifflin Company, 2002.

[56] L. Tomei and R. Morris, ICTs for Modern Educational and Instructional Advancement. Information Science Reference, 2009.

[57] P. Andreev and H. Maoz, "Validating Formative Partial Least Squares ( PLS ) Models : Methodological Review and Empirical Illustration," AIS Electron. Libr., 2009.

[58] M. Sarstedt, C. M. Ringle, D. Smith, R. Reams, and J. F. Hair, "Journal of Family Business Strategy Partial least squares structural equation modeling ( PLS-SEM ): A useful tool for family business researchers," J. Fam. Bus. Strateg., vol. 5, no. 1, pp. 105-115, 2014.

[59] W. W. Chin, "The partial least squares approach for structural equation modeling.," Mod. methods Bus. Res., no. April, pp. 295-336, 1998.

[60] H. C. Sox, "Medical Professionalism in the New Millenium: A Physician Charter," Ann. Intern. Med., vol. 136, no. 3, pp. 243-246, 2002.

[61] L. A. Anderson and R. F. Dedrick, "Development of the Trust in Physician Scale: A Measure to Assess Interpersonal Trust in PatientPhysician Relationships," Phsycological Reports, no. November, 1990.

[62] K. Quinn, "A Multi-Faceted Model of Trust that is Personalisable and Specialisable," University of Dublin, Trinity College, 2006. 
APPENDICES

A. Convergent Validity of Formative Measure

\begin{tabular}{|c|c|c|c|c|c|c|}
\hline \multirow{2}{*}{\multicolumn{2}{|c|}{ Construct }} & \multirow{3}{*}{$\begin{array}{l}\text { Indicators } \\
\text { INT1 }\end{array}$} & \multicolumn{2}{|c|}{ Convergent Validity } & \multicolumn{2}{|l|}{ Internal Consistency Reliability } \\
\hline & & & \multirow{2}{*}{$\begin{array}{l}\text { Loading }>0.50 \\
0.739\end{array}$} & \multirow{3}{*}{$\begin{array}{l}\text { AVE }>0.50 \\
0.566\end{array}$} & \multirow{3}{*}{$\begin{array}{l}\text { Composite Reliability } 0.60-0.90 \\
0.722\end{array}$} & \multirow{3}{*}{$\begin{array}{l}\text { Cronbach' Alpha 0.60-0.90 } \\
0.722\end{array}$} \\
\hline \multirow{17}{*}{ EV } & \multirow{2}{*}{ INT } & & & & & \\
\hline & & INT2 & 0.765 & & & \\
\hline & \multirow{6}{*}{ ITG } & ITG1 & 0.777 & \multirow{6}{*}{0.504} & \multirow{6}{*}{0.857} & \multirow{6}{*}{0.852} \\
\hline & & ITG2 & 0.786 & & & \\
\hline & & ITG3 & 0.557 & & & \\
\hline & & ITG4 & 0.749 & & & \\
\hline & & ITG6 & 0.611 & & & \\
\hline & & ITG7 & 0.735 & & & \\
\hline & \multirow{4}{*}{$\mathrm{CFT}$} & CFT1 & 0.751 & \multirow{4}{*}{0.521} & \multirow{4}{*}{0.811} & \multirow{4}{*}{0.805} \\
\hline & & CFT3 & 0.573 & & & \\
\hline & & CFT4 & 0.768 & & & \\
\hline & & CFT5 & 0.776 & & & \\
\hline & \multirow{2}{*}{ PRT } & PRT1 & 0.764 & \multirow{2}{*}{0.570} & \multirow{2}{*}{0.726} & \multirow{2}{*}{0.726} \\
\hline & & PRT2 & 0.747 & & & \\
\hline & \multirow{2}{*}{ CRG } & CRG1 & 0.781 & \multirow{2}{*}{0.627} & \multirow{2}{*}{0.771} & \multirow{2}{*}{0.771} \\
\hline & & CRG2 & 0.803 & & & \\
\hline & FRS & FRS & 1.000 & 1.000 & 1.000 & 1.000 \\
\hline
\end{tabular}

B. Collinearity Statistics of Ethical Value

\begin{tabular}{|c|c|c|c|c|c|c|c|c|c|c|c|}
\hline \multicolumn{2}{|c|}{ Interaction } & \multicolumn{2}{|c|}{ Integrity } & \multicolumn{2}{|c|}{ Confidentiality } & \multicolumn{2}{|c|}{ Protection } & \multicolumn{2}{|c|}{ Caring } & \multicolumn{2}{|c|}{ Fairness } \\
\hline INT1 & 3.941 & ITG1 & 3.054 & CFT1 & 2.643 & PRT1 & 4.205 & CRG1 & 1.647 & FRS & 1.000 \\
\hline INT2 & 1.469 & ITG2 & 1.639 & CFT3 & 1.646 & PRT2 & 1.482 & CRG2 & 1.647 & & \\
\hline & & ITG3 & 1.259 & CFT4 & 1.534 & & & & & & \\
\hline & & ITG4 & 2.699 & CFT5 & 2.873 & & & & & & \\
\hline & & ITG6 & 1.420 & & & & & & & & \\
\hline & & ITG7 & 3.209 & & & & & & & & \\
\hline
\end{tabular}

C. Convergent Validity for Reflective Measures

\begin{tabular}{|c|c|c|c|c|c|}
\hline \multirow{2}{*}{ Construct } & \multirow{2}{*}{ Indicators } & \multicolumn{2}{|c|}{ Convergent Validity } & \multicolumn{2}{|l|}{ Internal Consistency Reliability } \\
\hline & & $\begin{array}{l}\text { Loading } \\
>0.50\end{array}$ & AVE $>0.50$ & Composite Reliability $0.60-0.95$ & Cronbach' Alpha 0.60-0.95 \\
\hline \multirow{8}{*}{ TW } & TW1 & 0.519 & \multirow{8}{*}{0.503} & \multirow{8}{*}{0.888} & \multirow{8}{*}{0.891} \\
\hline & TW2 & 0.657 & & & \\
\hline & TW3 & 0.675 & & & \\
\hline & TW4 & 0.769 & & & \\
\hline & TW5 & 0.674 & & & \\
\hline & TW6 & 0.708 & & & \\
\hline & TW7 & 0.816 & & & \\
\hline & TW8 & 0.809 & & & \\
\hline \multirow{2}{*}{$\mathrm{TP}$} & TP1 & 0.872 & \multirow{2}{*}{0.744} & \multirow{2}{*}{0.853} & \multirow{2}{*}{0.853} \\
\hline & TP2 & 0.853 & & & \\
\hline \multirow{2}{*}{ BSE } & BSE1 & 0.812 & \multirow{2}{*}{0.613} & \multirow{2}{*}{0.934} & \multirow{2}{*}{0.935} \\
\hline & BSE2 & 0.747 & & & \\
\hline
\end{tabular}

